\title{
Students' Perceptions of Accents: Enhancing Identity through Learning Strategies ${ }^{1}$
}

\section{(El acento según los estudiantes: fortalecimiento de la identidad mediante estrategias de aprendizaje)}

\author{
Vera Madrigal Villegas ${ }^{2}$ \\ Universidad Nacional, Costa Rica \\ Vivian Vargas Barquero ${ }^{3}$ \\ Universidad Nacional, Costa Rica
}

\begin{abstract}
Teaching a foreign language requires knowledge and a systematic study of the structure and development of the target language. Hence, appropriate customs should be taught within their respective social and cultural context to encourage positive attitudes and avoid stereotyping. This analysis addresses the need for language learners to associate different accents in order to become aware of their own identity and that of their interlocutors. Thus, teachers should enhance language instruction without value judgments and emphasize the importance of empathy in the English learning environment, as a way of fostering positive changes in students' reactions and prevent social stereotypes.
\end{abstract}

1 Elaborado con base en la ponencia presentada por las autoras en el IV Congreso Internacional de Lingüística Aplicada, llevado a cabo en mayo de 2013, en el Campus Omar Dengo, de la Universidad Nacional de Costa Rica. Recibido: 19 de abril de 2012; aceptado: 30 de julio de 2012. Original title: "Language Attitudes and Social Stereotypes: Avoiding Evaluative Reactions toward Accents in the Language Classroom."

2 Escuela de Literatura y Ciencias del Lenguaje. Correo electrónico: verimv23@yahoo.com

3 Escuela de Literatura y Ciencias del Lenguaje. Correo electrónico: vivianvrgs@gmail.com 


\begin{abstract}
resumen
La enseñanza de una lengua extranjera requiere el conocimiento y el estudio sistemático de la estructura y el desarrollo de la lengua meta. Por tanto, conviene presentar las costumbres que se consideran apropiadas dentro de su respectivo contexto social y cultural para promover actitudes positivas hacia la comunicación intercultural y evitar estereotipos. Este análisis señala la necesidad de que los estudiantes asocien diferentes acentos para que sean conscientes de su propia identidad y de la de su interlocutor. Consecuentemente, los educadores deben mejorar la enseñanza de idiomas para evitar juicios de valor y resaltar la importancia de la empatía en el entorno del aprendizaje del inglés, con el fin de propiciar cambios positivos en las reacciones de los estudiantes y evitar estereotipos sociales.
\end{abstract}

Keywords: L2 acquisition, education, accents, stereotypes, value judgments, awareness, cross cultural communication

Palabras clave: adquisición de una segunda lengua, educación, acentos, estereotipos, juicios de valor, conciencia, comunicación intercultural

\title{
Introduction
}

Acquiring a second language (L2) implies many challenges in intercultural communication. One of these challenges can be outlined in the exploration of the nature of social stereotypes that may help or hinder the students' learning of a target language in a foreign environment. Hence, the study of attitudes toward language must be carefully taken into account to teach students about the importance of sociolinguistic differences, with the purpose of helping them understand accents and form positive perceptions of them. Therefore, making learners aware of strategies to explore certain types of behavior and accents can be a useful approach to ease their comprehension of language variations through the analysis of differences in a communicative language learning class.

Speakers of a second language tend to associate a specific conception to an accent, as something distinct from what is considered as Standard English. Thus, L2 speech is considered to differ from 
that of native speakers, and L2 speakers can experience certain situations in which they become sensitive because of discriminatory treatment. Based on this reality, the main objective of this paper consists of analyzing social stereotypes and their consequences, so that English language professors can enhance effective cross-cultural communication through learning strategies that will help students in Costa Rica form positive attitudes toward their L2 speech. For this reason, we can compare how this process affects our native language and consequently the target language itself.

The following research questions oriented the topic addressed here: To what extent do perceptions and value judgments toward accents help or hinder a second language learner? What kind of judgments do students make toward speakers' accents in their native language? Is there any significant influence on accents in the EFL classroom?

It was hypothesized that making students aware of their own identities and analyzing social stereotypes toward accents can be used as a strategy to promote positive attitudes and enhance effective cross-cultural communication in the acquisition of English as a second language.

With the main objective of finding a way to promote positive attitudes toward accents in an undergraduate program in teaching English at the National University of Costa Rica (Bachillerato en la Enseñanza del Inglés para I y II ciclos de la Universidad Nacional, $U N A$ ), this study was guided by three specific objectives: determine the extent to which judgments are made toward accents in the EFL classroom; examine students' evaluative reactions and perceptions toward accent variations within their own language and the target language; and suggest a set of strategies to promote positive attitudes toward accents and avoid social stereotypes in EFL classrooms. 


\section{Social Stereotypes in Language Learning}

The presence of stereotypes against the accent of L2 speakers in the classroom serves as a justification for biased treatment seen in negative or rude behavior, such as mockery or different types of judgments. A study of language attitudes is carried out to shed light on stereotypes about certain accents which students have when learning an L2, and illustrate the relevance of teaching students about sociolinguistic variations as a basis for how speech should be perceived in order to create beliefs of major or minor status or prestige. ${ }^{4}$ For this reason, professors of a foreign language can make comparisons with the study of accent variations in their first language and try to increase awareness about how necessary it is to prevent misconceptions about a certain accent being superior, including their own accent. According to O'Grady, "the speech of second language learners can exhibit non-nativelike characteristics in any linguistic domain." 5 Actually, the speech of second language learners maintains a certain resemblance to the first language. For example, a native speaker of Spanish sounds different from a native speaker of French when they both speak the same second language.

Ryan and Giles explain how the general nature of social stereotypes affects communication between social groups:

Research in various parts of the world has shown that speakers of 'high' or 'powerful' speech styles are stereotyped in terms of competence and traits related to socioeconomic status, while speakers of 'low' or 'powerless' speech styles are stereotyped less favorably along these dimensions. In other contexts, however, the language varieties of many of the latter groups may be imbued with pride by their own speakers (and sometimes this is conceded by the dominant

4 Sali Tagliamonte, Analysing Sociolinguistic Variation (Cambridge, UK: Cambridge University Press, 2006).

5 William D. O'Grady, Mark Aronoff, John Archibald and Janie Rees-Miller, Contemporary Linguistics: An Introduction. (Boston: Bedford/St. Martin's, 2010) 394. 
group) and subordinate group members are stereotyped in terms of the more 'human traits' of solidarity, integrity, social attractiveness, and so on (as quoted in Coupland and Jaworski). ${ }^{6}$

A simplified definition of a stereotype denotes a special meaning or image shared by members of a particular group. Hence, the concept of stereotypes can be understood as a general representation of how a given social group speaks. Consequently, stereotypes are formed in the minds of individuals as they grow up within a specific cultural environment. This can cause students to share the same beliefs and exhibit certain types of behavior toward native or nonnative speakers of English. For instance, a given stereotype about the members of a specific social group can originate because of the way they speak, possibly due to their having a different tone or peculiar accent considered as a cause for laughter. This accent would not be considered that way if it were not based on popular stereotypes, previously taught or spread as amusing. In fact, the cause of laughter is not commonly seen as blameless or naive. In most cases, if an accent is funny for a number of different reasons, that reaction is felt to be cruel, rude or sarcastic. Thus, a sociolinguistic stereotype can be a shared impression, appearing more likely as a linguistic component of a cultural stereotype.

\section{Perception of Accents}

Stereotypes are based on at least an indication of an idea that then grows out of proportion. Individuals do not come up with stereotypes at random; there is a basis for them. ${ }^{7}$ Stereotypes appear when people perceive accents differently from their own speech style. For instance, a certain group of people might believe that an accent sounds soft, slow,

6 Nikolas Coupland and Adam Jaworski, Sociolinguistics: A Reader and Coursebook (Hamphshire: Palgrave Macmillan, 1997) 237.

7 Ronald Wardhaugh, An Introduction to Sociolinguistics (Malden, MA: Blackwell, 1986). 
loud or pleasant. When students are learning an L2 they need to know that there are common judgments and attitudes which can be biased. "Apart from sign language it is as impossible to speak without an accent as it is to speak without making any sound." ${ }^{\prime 8}$ Therefore, professors must include activities in which students can realize that they cannot deny the existence of an accent in their speech and in that of others. Students should avoid stigmatizing accents as something negative when learning a second language or when socializing.

Since every speaker is considered to have an accent, and different accents can exist for any given language, speakers of other languages will be inclined to imitate the variant associated with greater prestige. For example, a well-known misconception is that British English is the most prestigious variety of English; likewise, Spanish as spoken in Spain is considered by some as the most prestigious of Spanish dialects. In Stockwell's words, "[a]ccents and dialects that are geographically close to one another tend to be similar in form; gradually varying the further you travel away from them."

For example, a Costa Rican student can understand how accent variations can occur in English because the same happens in their own country. They can compare how the speech of people from a province, such as Puntarenas, differs clearly from that of Guanacaste. Although Costa Rica is a small country compared to the United States, many dialectal varieties can be found. Becoming aware of the variety of accents existing all over the world is crucial to avoid misjudging speech patterns. In additional, people often perceive speakers' accents in daily conversations; the way that people make use of language is a clear reflection of the place where they were born and their social status. Indeed, when people meet a new person, they habitually assign a positive or negative social value to that person's speech. These judgments are often unconscious and automatic.

8 Peter Stockwell, Sociolinguistics: A Resource Book for Students (London: Routledge, 2002) 3.

9 Stockwell, 6. 


\section{Basics and Consequences of Stereotyping Accents}

People from different places develop concepts that lead to multiple perceptions. Cauthen et al. refer to cognitive biases that result from and cause stereotypical perceptions of social groups as well as the behavioral consequences of perceptions. This can make it easier to understand the variety of ways in which humans are influenced by stereotypes and explain why they pay more attention to certain people or reject others. People tend to take past events as examples to support the way they interpret things as they do. "It is arguably just as important that stereotypes engender behavioral confirmation, help to sustain a positive social identity and so on, as that they should relate simply or directly to behavior" (Cauthen et al., as quoted in Coupland and Jaworski). ${ }^{10}$ Therefore, the fact that students perceive an accent as prestigious or inferior depends generally on previous background information, communication and behavior learned from prior experiences in their community or within their culture. In this paper, the researchers take this premise as a basis for the importance of preventing stereotypes toward accents during an L2 learning process.

\section{Method}

Studying stereotypes and language attitudes helps students avoid evaluative reactions. This is particularly the case when students interact with people from different backgrounds. As mentioned above, the aim of this study is to promote positive attitudes toward accents in the classroom while learning a second language to prevent social stereotypes. Three factors motivated this research: first, the variety of people from different nationalities settling in Costa Rica; second, the large number of Costa Ricans who are currently learning second languages; and third, the effort required by teachers to make students aware of the differences between one culture and another.

10 Coupland and Jaworski, 278. 
This is a stratified random sampling study which explains a sociolinguistic problem and offers teaching strategies to overcome it. For this purpose the following procedures were followed:

1. The researchers identified, in advance, a number of speakers who represent a realistic variety of foreigners living in CostaRica.

2. The researchers selected two groups of students who are at different levels of the English major mentioned above.

3. The subjects were chosen randomly from the two groups.

4. Recordings were played for the subjects and they rated their impressions toward each accent.

5. The subjects under study were stratified according to their evaluative attitudes and perceptions toward the recorded speakers which were correlated with aspects such as nationality, native language, social prestige, confidence, accent pleasantness, housing and employment.

\section{Participants and Materials}

The participants in this study came from two UNA groups. A total of forty-eight students were involved, all from the EFL major for future primary school English teachers. Twenty-four were finalyear students and the remaining twenty-four participants were second-year students. The study took place over two months, during the second semester of 2012. For the survey, the participants listened to seven recordings and rated their perceptions of the speakers' accents. This survey (see appendix) was the same for everyone and it was administered over a number of days under the same conditions for all groups. The researchers applied the same survey to both groups to determine whether students perceptions changed as they advanced in their major. Both levels of participants had already taken six courses where pronunciation, culture and second language acquisition had been addressed. 
This questionnaire is a partial replication of the work done by Sarah Wood on "speech style and social evaluation"11 (mentioned by Stockwell). This survey differs from Wood's in many aspects. The main issue here is the purpose of analyzing the perceptions of the accents of people speaking Spanish with a group of Latin American students from Costa Rica, to use the results to examine the existence of social stereotypes toward accents in the acquisition of second languages.

\section{Recordings}

Seven Spanish speakers were interviewed about their previous weekend's activities. The following nationalities are represented in these recordings: Costa Rican, Colombian, Brazilian, Nicaraguan, American, Chilean and Taiwanese. At the beginning of each recording, the participants were informed of the speaker's nationality. The survey was conducted in Spanish because some of these informants were learning Spanish as a second language and the rest are native Spanish speakers. Brief background information is provided in Table 1 on the profiles of the speakers who participated in the recordings, to provide a sense of their characteristics as individual speakers. 


\section{Table 1. Speakers' profiles}

\begin{tabular}{|c|c|c|c|c|c|c|c|}
\hline 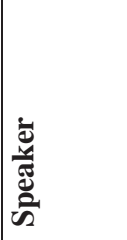 & $\stackrel{8}{4}$ & 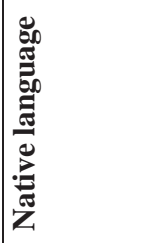 & 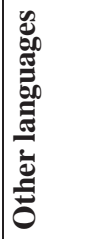 & 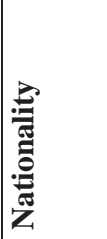 & 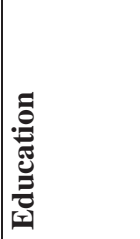 & 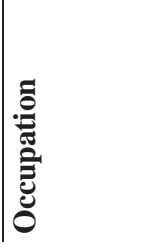 & 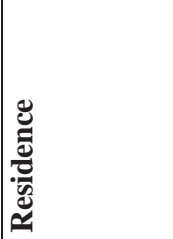 \\
\hline Hazel & 26 & Span. & Eng. & CR & $\begin{array}{l}\text { B.A. } \\
\text { EFL }\end{array}$ & $\begin{array}{l}\text { Eng. } \\
\text { teacher }\end{array}$ & $\begin{array}{l}\text { rented } \\
\text { apartment }\end{array}$ \\
\hline Rodrigo & 32 & Span. & Eng. & Colom. & $\begin{array}{l}4 \text { yrs. } \\
\text { high } \\
\text { school }\end{array}$ & $\begin{array}{l}\text { restaurant } \\
\text { owner }\end{array}$ & home owner \\
\hline $\begin{array}{l}\text { Regina } \\
\text { Mousini }\end{array}$ & 44 & Port. & Span. & Brazil & $\begin{array}{l}\text { lang. } \\
\text { teacher }\end{array}$ & $\begin{array}{l}\text { Portugese } \\
\text { teacher }\end{array}$ & $\begin{array}{l}\text { rented } \\
\text { apartment }\end{array}$ \\
\hline María & 37 & Span. & Eng. & Nicar. & secre-tary & $\begin{array}{l}\text { admin.asst. } \\
\text { UNA }\end{array}$ & $\begin{array}{l}\text { rented } \\
\text { home }\end{array}$ \\
\hline Holly & 22 & Eng. & Span. & USA & $\begin{array}{l}2 \text { yrs. } \\
\text { college }\end{array}$ & student & $\begin{array}{l}\text { rented } \\
\text { home }\end{array}$ \\
\hline Dorita & 26 & Span. & Eng. & Chile & 2 yrs. law & housewife & home owner \\
\hline $\begin{array}{l}\text { Wen } \\
\text { Chung }\end{array}$ & 25 & Mandarin & $\begin{array}{l}\text { Eng.; } \\
\text { Span. }\end{array}$ & Taiwan & $\begin{array}{l}3 \text { yrs. } \\
\text { college }\end{array}$ & student & home owner \\
\hline
\end{tabular}

\section{Results}

The analysis of the data gathered throughout the research is presented below. The main results are displayed in graphs portraying the most relevant findings for this project. There is a significant pattern of formulaic associations in attitudes to accents. A consensus exists across students' subjective evaluations of accents; this suggests that judgments about a speaker's accent tended to be rated consistently either as prestigious and pleasant, or as unprestigious and unpleasant. It is not surprising to note a pattern of common stereotypical associations shared among students. This brief summary of the findings shows students' perceptions, social stereotypes, and thoughts about specific accents. In general, the following tendencies were observed: 
- $\quad$ Nicaraguan and Taiwanese accents are believed to be unpleasant and not very prestigious.

- $\quad$ Brazilian and Chilean accents are considered pleasant and prestigious.

- The American accent is pleasant and very prestigious.

- The Colombian accent is neutral.

- The Costa Rican accent is prestigious and pleasant.

- Most Taiwanese people have their own business and home.

- Most Nicaraguans are blue-collar workers.

- Most Americans are students.

The following are specific results of this initial survey. In regard to question 1, concerning the confidence of the speakers while communicating their ideas, $44 \%$ said that the Taiwanese speaker was not very confident, $35 \%$ said that the Nicaraguan speaker was not very confident, $14 \%$ assumed that the Colombian speaker was not confident, $1 \%$ believed that the Brazilian and Chilean speakers were not confident, while $3 \%$ answered that the Costa Rican speaker was not confident either. Finally, $8 \%$ said that the American speaker was not confident.

Question 2 is about the students' view of accent unpleasantness. The results show that $74 \%$ of the subjects said that they find Nicaraguan accent unpleasant, $21 \%$ said they found Colombian accent unpleasant, $4 \%$ found the Costa Rican accent unpleasant, $48 \%$ thought that Taiwanese accent was very unpleasant, and 2\% considered Brazilian, Chilean and American accents unpleasant (figure 1). 


\section{Figure 1. Ratings of pleasantness of speakers' accent.}

\section{How would you rate the pleasantness of this speaker's accent?}

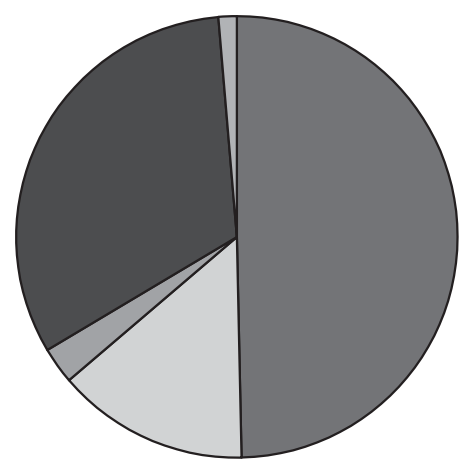

$74 \%$ Nicaraguan accent is unpleasant

$21 \%$ Colombian accent is unpleasant

$4 \%$ Costa Rican accent is unpleasant

$48 \%$ Taiwanese accent is very unpleasant

2\% Brazilian, Chilean and American accents are unpleasant

Question 3 refers to how students would rate the social prestige of a person's accent. Figure 2 shows that $50 \%$ of the respondents said the Nicaraguan accent is very unprestigious, another $50 \%$ said that the Taiwanese accent is unprestigious, 20\% answered that Costa Rican accent is unprestigous, 30\% said that American accent is very unprestigious, $20 \%$ said that Brazilian accent is unprestigious, $18 \%$ said Colombian accent is unprestigious, and 5\% felt Chilean accent is very unprestigious. 


\section{Figure 2. Ratings of prestige of speakers' accent.}

How would you rate the social prestige of this person's accent?

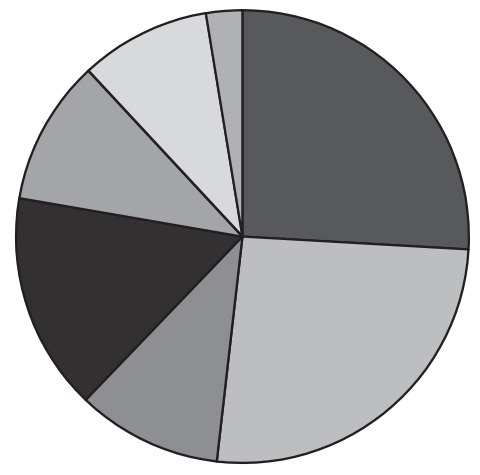

$50 \%$ Nicaraguan accent is very unprestigious

$50 \%$ Taiwanese accent is unprestigious

$20 \%$ Costa Rican accent is unprestigious

- $30 \%$ American accent is unprestigious

- $20 \%$ Brazilian accent is unprestigious

$18 \%$ Colombian accent is unprestigious

$5 \%$ Chilean accent is very unprestigious

In question 4, the students were asked about the type of housing that they would expect the person that they were listening to would live in. As shown in Figure 3, 33\% indicated that most Nicaraguans rent a place (such as a flophouse) where many people live together, $20 \%$ replied that Costa Ricans live in a rented house or apartment, $40 \%$ responded that Colombians live in a rented apartment, 25\% said that Brazilians own a house, $90 \%$ said that Americans live with a host family, $85 \%$ answered that Chileans own a house, and $95 \%$ believed that Taiwanese people own a house. 


\section{Figure 3. Ratings on the type of housing inferred from the speakers' accent.}

What type of housing would you expect this person to live in?
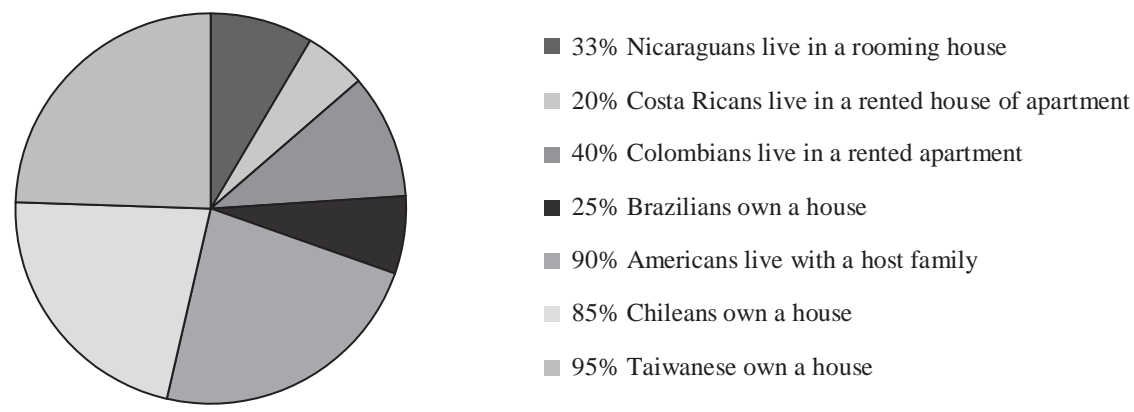

Finally, the results of question 5 (What type of job would this person have?) can be summarized as follows: It can be seen that $77 \%$ responded that Costa Ricans have a qualified job, $44 \%$ said that Colombians have a semi-skilled manual job, $82 \%$ responded that Brazilians have their own business, $65 \%$ replied that Nicaraguans have an unqualified jobs, $88 \%$ believed that Americans are unemployed, $32 \%$ said that Chileans work in an office, and that $91 \%$ of Taiwanese people own a business.

The results reveal some interesting stereotypes assumed by students. Since both groups provided very similar answers, it was found that there is no difference in terms of accent attitudes among second and fourth level students. Furthermore, a marked tendency can be observed in the students' stigmatization of speakers' social status, job and education. This study suggests that when people are not aware of the particular merits and prestige of each accent, they will often judge and evaluate accents based on stereotypes held in common by people in their own social group. 
Due to people's attitudes to different accents, it is essential to make students aware of the value of accent variation because of the interaction among people from different backgrounds that commonly takes place in Costa Rica. There is a clear link between the way that students stratify speakers according to their language, nationality and prestige. The most significant aspect of this research is its usefulness as a guiding principle for implementing teaching strategies in the language classroom addressed to preventing these students' negative and stereotyped perceptions.

\section{Increasing Awareness Through Classroom Strategies}

To emphasize the importance of teaching students how to avoid stereotypes toward accents in L2 learning, the strategies listed below have been proposed as a way to promote the avoidance of negative stereotypes in the language classroom:

1. Classroom discussions

2. Listing stereotypes

3. Critical thinking

4. Research projects and case studies

5. Anti-bias approach

6. Scenarios

7. Phonetics review

8. Conveying positive attitudes

\section{Classroom Discussions}

Constructive classroom discussions are useful for examining stereotypes from different points of view. They can lead to an exploration of the stereotypes existing in Costa Rica, and then the class can analyze them as to their basis in truth and the reasons for their existence. Both positive and negative stereotypes can be found. This can also take place by reflecting on TV shows and movies portraying 
Latin Americans or speakers of other languages such as Hindi, speaking English with an accent, as a source of humor. In this kind of class discussions, activities can be used basically to increase awareness of the existence of stereotypes and start a discussion about their validity. As a result, students can observe how people use stereotypes when forming opinions about other individuals who are foreign or just different from those in their own group.

\section{Listing Stereotypes}

Another strategy is to list the specific stereotypes to avoid. It is important to be precise as to why accents are stereotyped, and take actions to respond, at the same time being very careful with generalizations. Stereotypes must not become over-generalizations since they can represent a social stratification in which a higher status indicates money, prestige and power, or the contrary. Likewise, style stratification takes places in terms of formality of linguistic variables that occur in different social situations. ${ }^{12}$ The implementation of an anti-bias approach is an active and activist act of communicating which attempts to minimize the development of prejudice in the classroom. Educating by recognizing one's own biases and actively working through them is a strategy that can be exploited in adult learning. An anti-bias approach can be used to increase an awareness of the importance of conserving one's identity. ${ }^{13}$ No one should believe that accents make someone inferior. The following are features of anti-bias education for the L2 classroom, emphasizing the prevention of stereotypes toward accents:

- Instructors must appreciate themselves, where their students' come from, and all the groups they belong to, by building a sense of pride in their own identity, in their family history, and in their heritage. They must appreciate others who are different

12 Peter Trudgill, A Glossary of Sociolinguistics (Edinburgh: Edinburgh University Press, 2003).

13 Penelope Oakes and John Turner, Stereotyping and Social Reality (Oxford: Blackwell, 1994). 
and who belong to different groups, by learning that an L2 requires a knowledge of accent diversity.

- $\quad$ They must recognize that as a member of a certain group, they will be subject to prejudice and societal unfairness, so students need the ability to recognize bias, stereotypes and injustice, and know how to respond empathically. ${ }^{14}$

- $\quad$ One must learn how to respond to bias and unfairness by standing up for oneself or becoming an ally for someone else in other groups. The goal here is to have the ability to act, along with others, to strengthen a sense of community for creating cooperative language learning. ${ }^{15}$

\section{Critical thinking}

Critical thinking is a useful strategy to prevent stereotypes toward accents. When students are thinking critically, they are not simply thinking passively or accepting everything they see and hear. They are also thinking actively, sharing ideas and opinions, asking questions about what they observe, evaluating, categorizing, and finding relationships. Critical thinking activities such as relating theory to practice, making a claim and supporting it, using appropriate evidence, establishing links between ideas, asking questions and evaluating, will guide the student into a positive learning cycle. Through critical thinking activities, L2 students will be able to compare and contrast, identify cause and effect and therefore identify, describe and analyze problems to synthesize information, categorize facts and problems related to negative stereotypes, and identify solutions together.

\section{Research Projects and Case Studies}

Having students work on research projects and analyze case studies is one of the most useful strategies for the EFL classroom.

14 Marshall Rosenberg, Nonviolent Communication A Language of Life (Encinitas, CA: PuddleDancer, 2003).

15 Rosenberg, Speak Peace in a World of Conflict (Encinitas, CA: PuddleDancer, 2005). 
Through the examination of accents and stereotypes, students can conduct both primary and secondary research. By doing primary research, learners are able to get information from primary sources, such as other students, foreigners, educators, native speakers of Spanish and English. This will lead to the development of specific case studies. Regarding secondary research, learners of a foreign language can investigate the role of accents in L2 learning from sources such as books, journals, websites, and other theoretical resources, as a basis for developing productive insights on the topic. Case studies are more time-consuming, whether they are created or real. However, they have a number of advantages, such as developing an awareness of thought-provoking issues, applying problem-solving strategies; identifying characters' roles, fostering decision-making, examining data about characters and contexts, and promoting empathy. Students can trace aspects of accents directly from their main sources; they will learn from their own experiences and report accurate information in their findings that can be applied in their daily life, not only in the process of learning another language. ${ }^{16}$

\section{Anti-Bias Approach}

Regarding accents and stereotypes, signs of bias must be pointed out in a language class, since they could be perceived as a way to show an unreasonable like or dislike for a speaker's accent due to personal opinions. An anti-bias approach must be understood as instruction based on active methods that challenge prejudice, stereotypes and any other type of bias appropriately. This approach was developed by Louise Derman Sparks and Julie Olsen Edwards, educators who planned to implement it with children who had developed biases against people of different ethnicities, cultures, genders and abilities. They recognized that by teaching about their own bias,

16 Alison Mackey and Susan Gass, Second Language Research. Methodology and Design (Mahwah, NJ: Lawrence Erlbaum Associates, 2005). 
they could create a more tolerant classroom and generate a more open-minded society. ${ }^{17}$

Although their approach was designed to help children become broadminded, here the approach is oriented toward adults learning a second language, who should recognize and appreciate similarities and differences among accents. This approach uses appropriate, respectful, reflective language to refer to people from different communities and backgrounds. Thus, in higher education the goals of this anti-bias approach remain the same: develop a sense of pride in one's own identity and background; increase appreciation and knowledge of language and human diversity; develop the ability to recognize stereotypes, bias and injustice, in order to prevent them; and acquire the capacity to act alone or with others in one's and others' behalf.

Classroom activities must be focused on the above goals. This will enable students to understand that as EFL speakers, they themselves belong to a group which has a different accent, and at times may face prejudice. By learning how to respond to bias and unfairness by standing up for themselves and others, appreciating their background and that of others, these misconceptions will diminish and cross-cultural communication will be improved.

\section{Scenarios}

The use of scenarios in EFL is a useful tool enabling students to imagine themselves in a certain position and experience how they would feel in different roles in various situations. A scenario is a detailed description of a possible action or event that might exist or that the student may face in the future. Each scenario presents students with challenges and tasks that they come up against, in order to for them to experience a situation and find a solution. When analyzing accents and the causes of stereotyping them, teachers may choose scenarios from real-life situations or they can be made up and

17 Louise D. Sparks and Julie O. Edwards, Anti-Biased Education for Young Children and Ourselves (2010). Web. 16 Aug. 2013. 
adapted to the students' contexts and language levels. For instance, one scenario could be as follows:

Scenario 1: You are a Colombian student who has just moved to Costa Rica. You are attending an Oral Expression Class in English. You are discussing sustainability issues in groups, and everyone has given his/her own opinion. When it is your turn, one of your classmates suddenly interrupts you and asks: "Hey, you are a foreigner, aren't you? You have an accent. Are you Cuban?"

Talk about your reaction. How do you feel? Why?

Scenarios like the above give students the chance to either dramatize the situation, or analyze it in pairs or small groups. Then the students would have the opportunity to share their ideas with the whole class, and compare or contrast opinions. Finally, a deeper analysis of the situation is shared in plenary and the students could go beyond and understand not only what an accent will sound like, but the cultural connotations involved in order to learn how to deal with accents in "real life."

\section{Phonetics Review}

The study of phonetics and phonology of an L2 provides an excellent opportunity for students to realize the importance of analyzing how accents differ from each other, and why they do not have to be a cause for stereotyping. Teachers can point out that in certain accents, stress (or the prominence given to syllables of words within utterances by using certain pitch) may vary, and attention may be focused on the different pronunciations of a particular word. At the same time, teachers can indicate that any specific language may vary; in this case, they can give examples of people from the same country and speaking the same language (such as Americans speaking English, living in different regions of the United States). 
Peter Roach, in his "English Phonetics and Phonology Glossary,"18 refers to "accent," (as used in the survey conducted) as "a particular way of pronouncing," and goes on to state that different speakers of the same language who are from different places (both native and nonnative speakers) will all be sharing the same grammatical structures and vocabulary, but pronouncing or stressing utterances differently.

Diverse accents have different intonation, so the use of listening discrimination activities will provide students with additional real-life like practice in distinguishing the differences. Another way to clarify this issue is through the use of controlled practice in the classroom by having students predict prominence in a dialogue performed by a couple of English speakers from two or more specific places. For instance, two students could read the same dialogue with an Irish accent or an Australian accent, and then they would listen to it and identify differences in the production of certain phonemes.

A similar activity could be assigned to students by using their native language. In Costa Rica, students can write a small dialogue and then look for speakers of Spanish to read it aloud and record it. They would find many interesting results about the volume, length and pitch; the same would happen in English or in any other language. Celse-Murcia recommends guided and communicative practice throughout her book. ${ }^{19}$ Although the use of role-plays and model dialogues may be considered an old-fashioned strategy, it is actually very effective in the analysis of accents. Students become more aware of accent differences and realize that they should not judge accents while they practice and improve their knowledge of intonation patterns in an L2. The teaching of intonation is, therefore, enhanced by the development of an awareness of cultural identity.

18 Peter Roach, "English Phonetics and Phonology Glossary.” Web. 16 Aug. 2009,

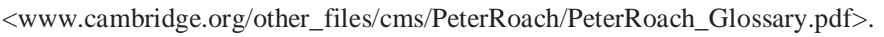

19 Marianne Celce-Murcia, Teaching Pronunciation (Cambridge: Cambridge University Press, 1996). 


\section{Conveying Positive Attitudes}

Some teaching techniques can enhance students' participation more than others. Having enjoyable classroom activities, learners feel more open-minded to different tasks because their attention span is longer and they are more receptive. An encouraging atmosphere is vital for getting good results in any type of activity. By incorporating collaborative work in the EFL classroom, students can benefit from the others' participation. Through short-term or long-term projects, students will have more opportunities to do research and analyze the existence of stereotypes in accents. Perhaps they will also discover that the ultimate goal will be to work with others to prevent bias, and find ways to create a positive view of diversity in language learning.

By promoting a positive attitude, students are more motivated to work and learn. Positive attitudes help learners in the process of acquiring an L2. The implementation of the above techniques will boost their self-confidence toward their own accent and identity. Optimistic students make constructive contributions to the class, come up with ideas to create a better classroom environment, and also learn how to advise society on empathy and non-violent communication.

\section{Final Considerations}

Students have to communicate with people from different cultures and be aware of foreign accents and their own without making judgments. To reduce stereotyping, English language professors should acknowledge the importance of activities to promote crosscultural values. By preventing negative connotations toward accents, instructors can develop ways for students to realize the existence of accent variations and analyze the consequences that this has when learning a foreign language. Otherwise, the EFL learners could limit their learning and not extend their perceptions of accents. The results of the survey conducted suggest that there is an urgent need to be aware of the different accents that can be found in our country. 
Language teachers may not devote enough time to these variations. The study shows how neglected this aspect is.

In education there should be no judgments of any kind, in order to learn to connect empathically with others. By implementing strategies based on a non-bias approach, students can get a broader view of others' culture and accents, and understand why some people behave one way or another. The significant influence that accents play in L2 learning cannot be ignored. Having students compare their own culture and accents within their native language has shown itself to be a useful strategy. Students should be able to understand differences and behavior that lead to prejudice and stereotypes, and thus learn how to prevent them. The application of the strategies suggested here will be the core of future research.

Due to the need that teachers have to implement activities that prevent negative stereotypes, the strategies proposed above serve to review the implications of integrating social and linguistic aspects of language. The study of language attitudes toward accents must emphasize the importance of a subjective perception in L2 learners, who should be aware of their own culture, language and attitudes, for more effective communication skills.

\section{Appendix}

\section{Cuestionario de percepciones $\mathbf{y}$ juicios de valor sobre acentos}

Instrucciones: A continuación usted evaluará el acento de siete personas según el juicio de valor que usted determine conveniente. Antes de contestar, familiarícese con las siguientes preguntas y sus correspondientes opciones de respuesta. Cuando escuche las respectivas grabaciones, escriba las respuestas según sus percepciones. 


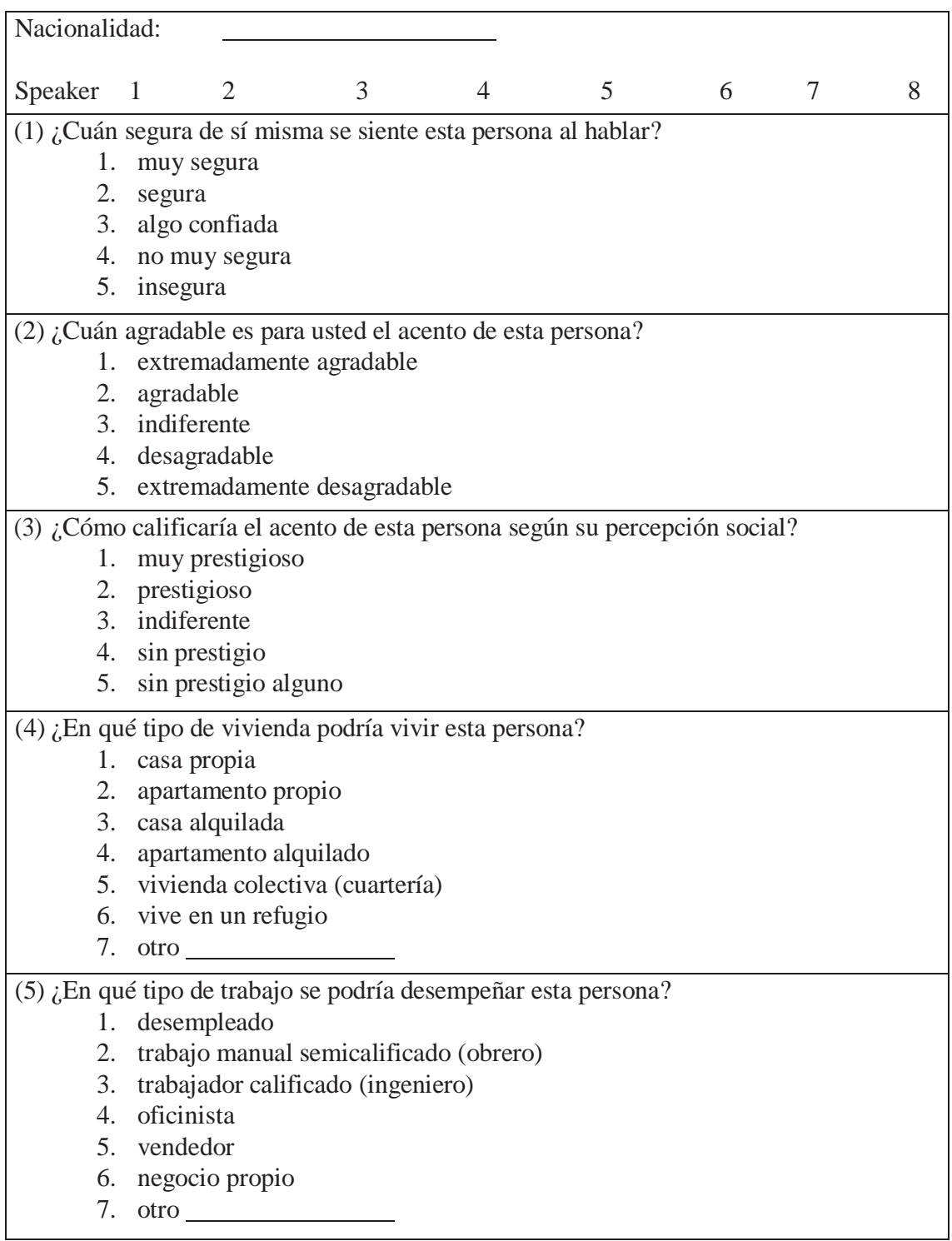

